\section{PLASMA OVERLAY WELDING OF COBALT ALLOY}

MARIAN SIGMUND

Faculty of Mechanical Engineering, Institute of Welding and Surface Treatment, Brno, Czech Republic

10.17973/MMSJ.2019_10_2018132

sigmund@fme.vutbr.cz

This article describes the overlay welding of a cobalt alloy. This overlay is made by the plasma transfer arc (PTA) welding technology. Cobalt alloy is overlaid on a creep resistant steel as the seat of a high-pressure steam valve. High-pressure steam valves are used in the energy, nuclear, petrochemical, oil, gas and pharmaceutical industries. Creep resistant high alloy steels are weldable with proper welding conditions, including stress relieving. Cobalt alloys, on the other hand, have worse weldability. Overlay welding of these heterogeneous materials is possible as well with meeting specific conditions especially proper welding parameters. In this article, the whole experiment is described, including design of the part that is overlaid by plasma arc welding. The technological procedure of overlay welding is described, including a description of the welding equipment, subsequent evaluation and all standards and specified inspections needed for welding procedure qualification (WPQR). WPQR qualification of overlay welding was also done and finished with Notify Body.

KEYWORDS

Cobalt alloy - Stellite, creep resistant steel, overlay welding, plasma transfer arc (PTA) welding, valve seat, metal powder, preheating, hardness, $p$ WPS, WPQR, WPS.

\section{INTRODUCTION}

During welding, overlay welding, surface treatment, renovation by overlay welding or by thermal spray coating, especially for the energy, nuclear, petrochemical, oil and gas and also for the pharmaceutical industries, strong emphasis is placed on high quality, functional reliability or guaranteed lifetime of the component. Individual parts of the equipment operating in these industries, should at the same time feature creep resistance at high temperatures and high pressures in the steam and also corrosion and wear resistance. For example, high-pressure steam valves and also valve seats are produced from a creep resistant steel. For this specific case are valve seats most often overlaid by cobalt alloys, especially Stellite 6 or Stellite 21 . Generally, conventional overlay welding technologies can be used, such as manual by coated or full wire electrode overlay welding, or by submerged arc welding (SMAW) or gas tungsten arc overlay welding (GTAW) in inert gas; alternatively, by the automatic non-conventional overlay welding processes like laser overlay welding or plasma overlay welding (PTA). Valve seats are produced from different alloyed and creep resistant steels (Table 1) and are commonly overlaid by various types of cobalt alloys (Table 2). For mass production, automated overlay welding by PTA is typically used, while manual GTAW overlay welding is commonly used only for small surface defects. Our study is focused on a valve seat from X10CrMoVNb9-1 base material, plasma overlay welded with Stellite 21 cobalt alloy powder. This type of cobalt alloy is designed for the most suitable performance concerning creep, corrosion and wear resistance during high temperatures and pressures in the abovementioned application fields.

\begin{tabular}{|l|l|}
\hline P265GH & $\begin{array}{l}\text { Carbon unalloyed creep resistant } \\
\text { steel }\end{array}$ \\
\hline Mo low alloy creep resistant steel \\
\hline 13 CrMo4-5 & $\begin{array}{l}\text { Cr-Mo low alloy creep resistant } \\
\text { steel }\end{array}$ \\
\hline 10CrMo9-10 & $\begin{array}{l}\text { Cr-Mo low alloy creep resistant } \\
\text { steel }\end{array}$ \\
\hline X20CrMoV12-1 & $\begin{array}{l}\text { Cr-Mo-V martensitic creep } \\
\text { resistant steel }\end{array}$ \\
\hline X10CrMoVNb9-1 & $\begin{array}{l}\text { Cr-Mo-V-Nb martensitic creep } \\
\text { resistant steel }\end{array}$ \\
\hline X10CrWMoVNb9-2 & $\begin{array}{l}\text { Cr-Mo-V-Nb-W martensitic creep } \\
\text { resistant steel }\end{array}$ \\
\hline
\end{tabular}

Table 1. Creep resistant steels used for valve seat production

\begin{tabular}{|l|l|} 
Stellite 6 & $\begin{array}{l}\text { Cr-W Cobalt alloy } \\
\text { (max. hardness 45 HRC) }\end{array}$ \\
\hline Stellite 21 & $\begin{array}{l}\text { Cr-Mo Cobalt alloy } \\
\text { (max. hardness 40 HRC) }\end{array}$ \\
\hline Stellite 25 & $\begin{array}{l}\text { Cr-W-Ni Cobalt alloy } \\
\text { (max. hardness 45 HRC) }\end{array}$ \\
\hline
\end{tabular}

Table 2. Types cobalt alloys used for valve seat overlay welding

\section{OVERLAY WELDED PART}

High-pressure valve (Figure 1 ) is designed to reduce the pressure and temperature of steam from the high pressure to low pressure parts of the system. Detail of high-pressure valve seat is shown in Figure 2. The base material of the valve seat in this experiment is creep resistant steel X10CrMoVNb9-1 (1.4903, ASTM 182 F91). Chemical composition of the base material is described in Table 3. The valve seat is overlaid by Stellite 21 cobalt alloy. Chemical composition of this cobalt alloy is described in Table 4.

\begin{tabular}{|l|l|l|l|l|l|l|}
\hline $\mathbf{C}$ & $\mathbf{S i}$ & $\mathbf{M n}$ & $\mathbf{N i}$ & $\mathbf{P}$ & $\mathbf{S}$ & $\mathbf{C r}$ \\
\hline 0,08 & Max. & 0,30 & Max. & Max. & Max. & 8,0 \\
\hline 0,12 & 0,50 & 0,60 & 0,40 & 0,025 & 0,015 & 9,5 \\
\hline Mo & $\mathbf{V}$ & $\mathbf{N}$ & $\mathbf{N b}$ & $\mathbf{A l}$ & & \\
\hline 0,85 & 0,18 & 0,03 & 0,06 & Max. & & \\
\hline 1,05 & 0,25 & 0,07 & 0,1 & 0,03 & & \\
\hline
\end{tabular}

Table 3. Chemical composition of creep resistant steel X10CrMoVNb9-1

\begin{tabular}{|l|l|l|l|l|l|l|}
\hline Co & Cr & C & Ni & Mo & Fe & Si \\
\hline Base & 26 & 0,20 & 2,0 & 4,5 & Max. & Max. \\
\hline & 29 & 0,35 & 3,0 & 6,0 & 2,0 & 2,0 \\
\hline
\end{tabular}

Table 4. Chemical composition of cobalt alloy Stellite 21 


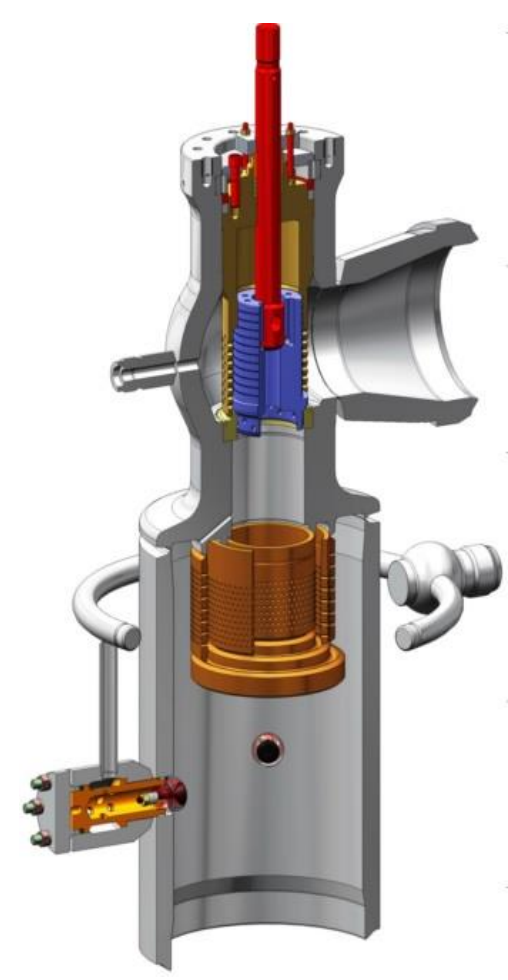

Figure 1. High-pressure valve

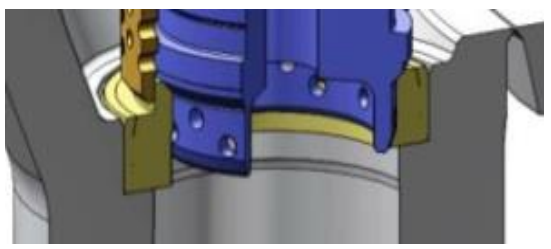

Figure 2. Detail of high-pressure valve seat

During plasma overlay welding, high concentration plasma flow is used. The advantage of using a plasma transfer arc lies in the possibility to independently and simply regulate the amount of heat input and also consumed filler material during the overlay welding. Hence it is possible to achieve optimum heat regime on the overlay welded part. For our experiment, argon plasma was used, reaching a temperature as high as $16000 \mathrm{~K}$. Besides the plasma gas, argon was also used as focusing gas for necking plasma beam and as shielding gas for weld pool protection.

\subsection{Equipment for plasma overlay welding}

For in-house plasma overlay welding of the valve seat sample by a metal powder, a PPC 250 PTM plasma overlay automatic machine from Czech producer KSK, Ltd Ceska Trebova was used. The machine is displayed in Fig. 3. It is capable of overlay welding of rotary parts on flat or curved faces (parts as valve seats, valve plugs and ninepins, diffusers, spindles, plates and so on) by PTA. This system provides burner positioning controlled in three axes, positioner face single parts controlled in two axes, programming by method "demonstrate and perform", programming in dialog, overlay welding by metal powder and overlay welding by hot or cold wire. For plasma welding, two modes of burner wiring exist. First is dependent (Fig. 4), in which the anode is wired to the base material and the cathode is wired to the tungsten electrode. Auxiliary power source creates enough conductive field for ignition of the primary arc. This wiring is used for plasma arc welding, plasma overlay welding and plasma cutting. Second wiring is independent, where both poles are wired to the tungsten electrode. This wiring is used for plasma surface hardening and plasma spraying.

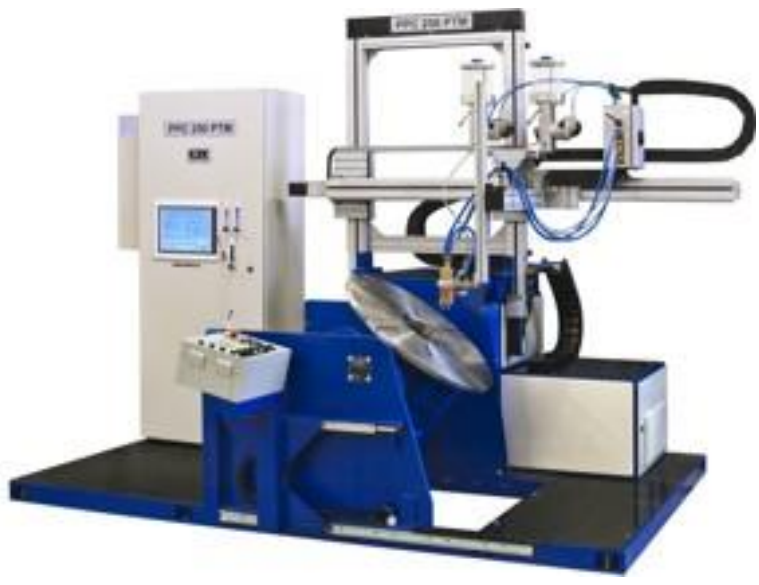

Figure 3. Plasma overlay welding machine type PPC 250 PTM

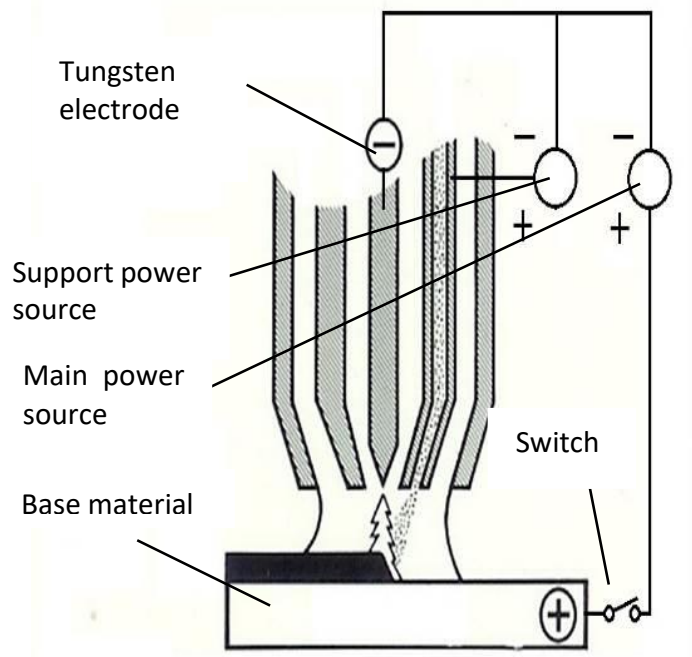

Figure 4. Plasma burner wiring (settings for plasma overlay welding)

\subsection{Plasma burner}

For overlay welding, a PHP 250 S plasma burner was used. The design of this burner is in Fig. 5 and technical specifications are in Tab. 5.

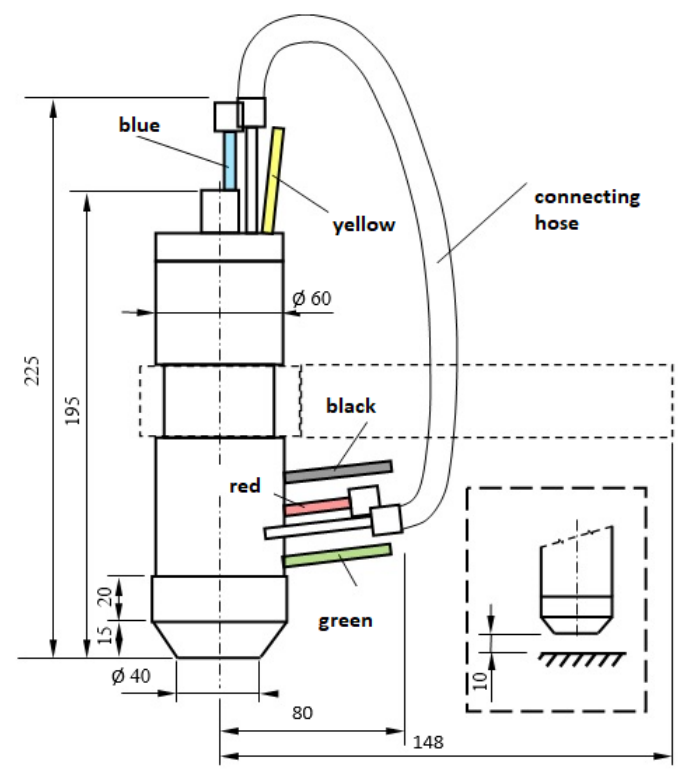

Figure 5. PHP 250 S plasma burner 


\begin{tabular}{|c|c|c|}
\hline Welding Current & \multicolumn{2}{|c|}{200 A at $100 \%$ Duty cycle } \\
\hline I (A) & \multicolumn{2}{|c|}{$250 \mathrm{~A}$ at $60 \%$ Duty cycle } \\
\hline Tungsten Electrode & \multicolumn{2}{|c|}{$\varnothing 4,0 \times 175 \mathrm{~mm}$} \\
\hline Plasma Gas & $\operatorname{Ar} 4,6$ & Consumption $2-5 \mathrm{l} / \mathrm{min}$ \\
\hline Shielding Gas & $\operatorname{Ar} 4,6$ & Consumption 8-15 I/min \\
\hline Focusing Gas & $\operatorname{Ar} 4,6$ & Consumption $2-5 \mathrm{l} / \mathrm{min}$ \\
\hline Burner cooling (10I) & \multicolumn{2}{|c|}{ Inlet $\mathrm{H}_{2} \mathrm{O}$ and Welding Current } \\
\hline De-mineralized & \multicolumn{2}{|c|}{ Outlet $\mathrm{H}_{2} \mathrm{O}$ and Pilot Current } \\
\hline Powder Feeder & \multirow{2}{*}{\multicolumn{2}{|c|}{$\begin{array}{l}\text { Powder Granularity 50-200 [ } \mu \mathrm{m}] \\
\text { Powder feed 3-40 [rpm] }\end{array}$}} \\
\hline$(12 \mathrm{~kg})$ & & \\
\hline
\end{tabular}

Table 5. Technical specification of the PHP 250 S plasma burner

\subsection{Valve seat overlay welding}

During the experiment, Stellite 21 was overlay welded by PTA on rough machined valve seat sample, with thickness addition for machining after overlay welding. Since the base material is creep resistant steel X10CrMoVNb9-1, it is necessary to apply flame preheating before overlay welding. The preheating temperature must be above $250^{\circ} \mathrm{C}$. The temperature was measured by a contact thermometer. The process of plasma overlay welding is shown in Fig. 6. Plasma weld overlay characteristics of single layers were recorded during overlay welding and are described in Table 6.

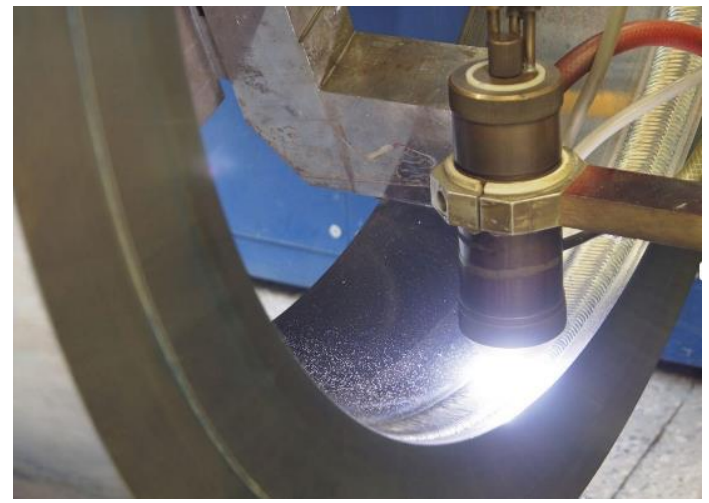

Figure 6. Process of overlay welding on valve seat sample

\begin{tabular}{|l|l|l|l|l|l|} 
& I $(\mathrm{A})$ & $\begin{array}{l}\text { Wiggle } \\
(\mathrm{mm})\end{array}$ & $\begin{array}{l}\text { Pulse } \\
(\mathrm{s})\end{array}$ & $\mathrm{V}(\mathrm{m} / \mathrm{s})$ & $\mathrm{T}\left({ }^{\circ} \mathrm{C}\right)$ \\
\hline $\mathbf{1}^{\text {st }}$ layer & 165 & 15 & $0,3 / 0,3$ & 10 & 280 \\
\hline $\mathbf{2}^{\text {nd }}$ layer & 160 & 15 & $0,3 / 0,6$ & 10 & 305 \\
\hline $\mathbf{3}^{\text {rd }}$ layer & 160 & 15 & $0,3 / 0,6$ & 10 & 298 \\
\hline $\mathbf{4}^{\text {th }}$ layer & 160 & 15 & $0,3 / 0,3$ & 10 & 290 \\
\hline $5^{\text {th }}$ layer & 160 & 15 & $0,3 / 0,3$ & 10,5 & 285 \\
\hline $6^{\text {th }}$ layer & 160 & 15 & $0,3 / 0,3$ & 10,5 & 285 \\
\hline & \multicolumn{5}{l}{ Voltage 23-25 V } \\
\hline
\end{tabular}

Table 6. Plasma weld overlay characteristics
2.4 Valve seat post weld heat treatment, machining, and DT / NDT testing

Immediately after plasma overlay welding by metal powder, sample was slowly cooled down in silica sand and consequently stress relieved in an oven at $750^{\circ} \mathrm{C}$ with two hours holding time at this temperature. Diagram of stress relieving is displayed in Figure 7. The stress relieving was followed by a visual inspection of weld overlay according to standard EN ISO 15614-7. Visual inspection did not reveal any defects. Afterwards, penetrant inspection according to standard EN ISO 15614-7 was performed on the rough machined valve seat sample. The sample was without line indications on surface and cracks, therefore, has passed the non-destructive testing (NDT) as suitable. Subsequently, evaluation of macrostructure (Figure 8) and microstructure (Figure 9) of weld overlay and heat affected zone according to standard EN ISO 17639 was performed. Finally, hardness (HV10) was measured across the weld overlay according to standard EN ISO 9015-1. Graph of hardness measurement is shown in Figure 10. On the weld overlay, hardness above 378 HV10 was recorded. Minimum guide value of hardness of weld overlay by Stellite 21 is $27 \mathrm{HRC}$, which corresponds to $279 \mathrm{HV} 10$. The measured hardness values are higher; thus hardness is also suitable. On real products (valve seats), destructive testing (DT) is normally not done. Shall be effected only experimentally on a sample to check suitable results. Real product (valve seat) is consequently finished by machining according to final drawing dimensions.

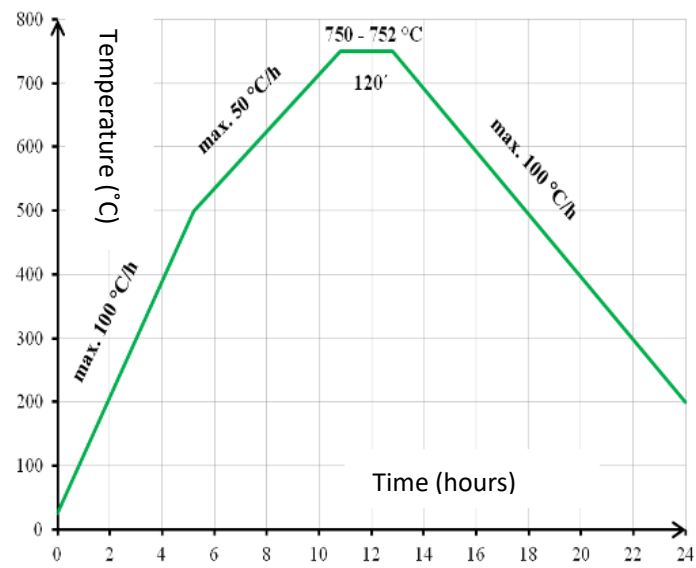

Figure 7. Diagram of stress relieving (post weld heat treatment)

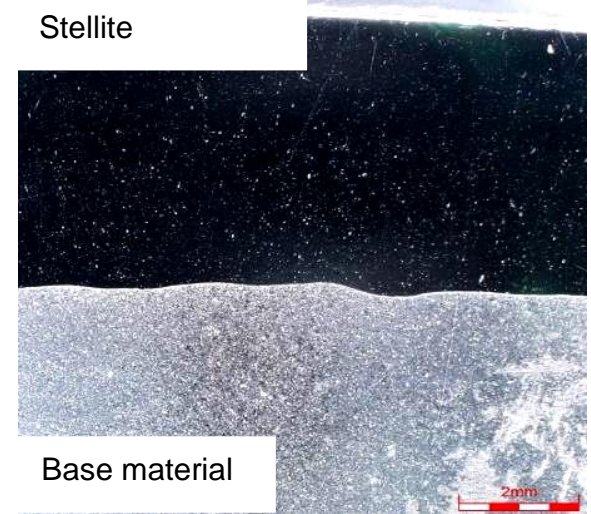

Figure 8. Macrostructure of weld overlay (without defects)

$\mathrm{I}=160 \mathrm{~A}, \mathrm{U}=24 \mathrm{~V}, \mathrm{v}=0,1 \mathrm{~cm} / \mathrm{min}$. Plasma weld overlay by Stellite 21 on base material X10CrMoVNb9-1. 


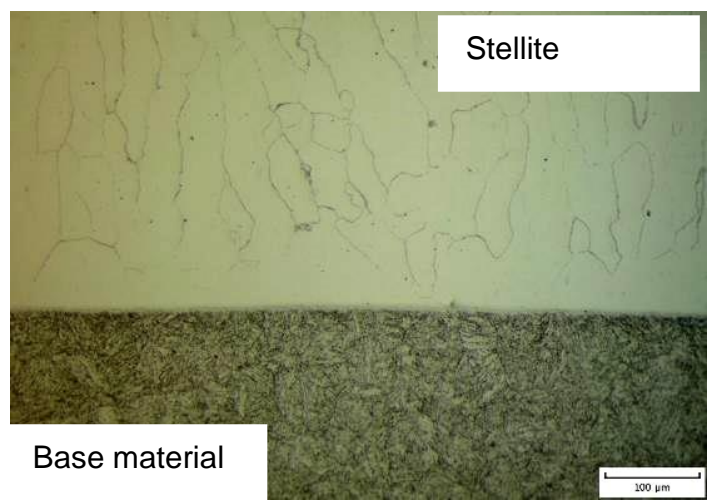

Figure 9. The microstructure of weld overlay (100x zoom) (without defects)

$\mathrm{I}=160 \mathrm{~A}, \mathrm{U}=24 \mathrm{~V}, \mathrm{v}=0,1 \mathrm{~cm} / \mathrm{min}$. Plasma weld overlay by Stellite 21 on base material X10CrMoVNb9-1. Weld overlay is austenitic cobalt solid solution with primary precipitated chromium and molybdenum carbides. The base material has fully martensitic microstructure.

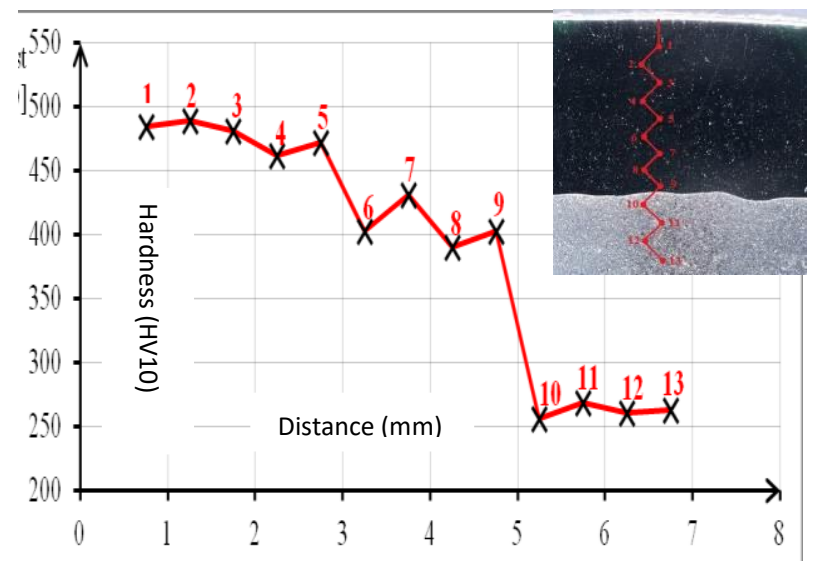

Figure 10. Graph of HV 10 hardness measurement

$\mathrm{I}=160 \mathrm{~A}, \mathrm{U}=24 \mathrm{~V}, \mathrm{v}=0,1 \mathrm{~cm} / \mathrm{min}$. Plasma weld overlay by Stellite 21 on base material X10CrMoVNb9-1.

In the macro and microstructure of weld overlay, in the heat affected zone after weld overlaying and also after the post weld heat treatment, there weren't identified any defects and inhomogeneities of microstructure, which was in addition confirmed by hardness measurement. Therefore, according to destructive (DT) and also non-destructive (NDT) testing, the weld overlay is considered suitable.

\section{EXPERIMENT EVALUATION}

Plasma weld overlay by a Stellite 21 metal powder on a valve seat sample from creep resistant steel X10CrMoVNb9-1 was performed. Based on the destructive and also non-destructive testing results, it is considered suitable and also fulfills the standard for overlay welding qualification EN ISO 15614-7. Consequently, pre-overlay welding procedure (pWPS) was approved and during NoBo supervision this overlay welding process was qualified by welding procedure qualification report (WPQR). After evaluation and checking the given overlay welding technology by the described manufacturing procedure, a weld overlay procedure (WPS) was created according to appropriate practical experience standard EN ISO 15609- 1. To avoid possible cold cracks formation (as the base material is creep resistant martensitic stainless steel), it will be necessary to observe the minimum preheating temperature $250^{\circ} \mathrm{C}$. After the overlay welding, slow cooling down in silica sand or in the wrap should be applied, possibly also post-heating. These steps are applied to ensure even distribution of heat input during the overlay welding, as well as slow heating and cooling down after the overlay welding. The main reason is the prevention of cold cracks formation, induced by residual diffused hydrogen in the martensitic microstructure. For the same reason, it will be necessary to observe proper heat input and heat regime of post weld heat treatment. For experiment evaluation, as well as during future production, proper preparation including mechanical cleaning (brushing) of overlaid weld between single layers, is essential. This is important to prevent incompletely penetrated beads, cold joints and impurity inclusions between the layers. All these defects may cause crack initiation during post stress relieving and constitute a reason for unsatisfactory nondestructive and destructive test outcomes. In light of all described overlay welding and technological parameters, it is also recommended, along with visual tests, to perform also penetrant tests on the weld overlay for detection of possible surface defects that are not visually identified. Only when the test outcome is satisfactory, one should proceed to the stress relieving step, thereby avoiding possible extra costs from stress relieving parts with defects.

\section{CONCLUSIONS}

Plasma overlay welding of cobalt alloy on creep-resistant steel parts solves a whole number of actual problems of the energy industry - for example, heterogeneous weld joints, including specific weldability of these hardly weldable materials. In this article, a pilot experiment is described, including plasma overlay welding qualification and testing procedure of specific cobalt alloy on a specific product, as well as the evaluation of possible risks. During this study, a specific overlay welding procedure was tested and qualified. This serves as a pilot experiment for the qualification of a whole number of subsequent overlay welding procedures.

\section{ACKNOWLEDGMENTS}

I would like to thank cooperative company CCI IMI Brno, where were realized in-house plasma overlay welding and also VUT FSI Brno, where were realized resulting evaluate examinations.

\section{REFERENCES}

[WASET 2012] WASET. Temperature-Dependence of Hardness and Wear Resistance of Stellite Alloys [online]. 2012 [cit. 2018-03-16]. Available from http://waset.org/publications/5340/temperaturedependence-of-hardness-and-wearresistance-ofstellite-alloys.

[AZOM 2013] AZOM. Stellite Alloys - Chemical Composition, Mechanical Properties and Common Applications [online]. 2013 [cit. 2018-03-16]. Available from http//www.azom.com/article.aspx? ArticlelD=9857

[KSK 2015] Manual for welding machine PPC 250 PTM, KSK. Brno, 2015.

[IMI CCI 2007] General guidelines for hardfacing on to steel substrates. IMI CCI, Brno, 2007. 


\section{CONTACT}

Ing. Marian Sigmund, Ph.D.

FSI VUT Brno, Faculty of Mechanical Engineering,

Institute of Welding and Surface Threatment,

Technicka 2896/2, Brno 616 69, Brno, Czech Republic

+420 54114 2611, sigmund@fme.vutbr.cz 